\title{
Antireflux Surgery in Korea: A Nationwide Study from 2011 to 2014
}

\author{
Jun-Hyun Lee ${ }^{1}$, Joong-Min Park ${ }^{2}$, Sang-Uk Han ${ }^{3}$, Jin-Jo Kim ${ }^{1}$, Kyo Young Song ${ }^{1}$, Seung Wan Ryu ${ }^{4}$, Kyung Won Seo ${ }^{5}$, Hyoung-
} II Kim ${ }^{6}$, Wook Kim ${ }^{1}$, and Korean Antireflux Surgery Study (KARS) Group

${ }^{1}$ Department of Surgery, The Catholic University of Korea College of Medicine, ${ }^{2}$ Department of Surgery, Chung-Ang University College of Medicine, Seoul, ${ }^{3}$ Department of Surgery, Ajou University School of Medicine, Suwon, ${ }^{4}$ Department of Surgery, Keimyung University School of Medicine, Daegu, ${ }^{5}$ Department of Surgery, Kosin University College of Medicine, Busan, and ${ }^{6}$ Department of Surgery, Yonsei University College of Medicine, Seoul, Korea

Background/Aims: Although laparoscopic fundoplication is a well-established therapy for gastroesophageal reflux disease (GERD) in Western countries, the mainstay of GERD treatment in Korea is long-term proton pump inhibitor (PPI) use. The aim of the present study was to evaluate nationwide data regarding antireflux surgery in Korea. Methods: Data from 2011 to 2014 were collected from the Korean Antireflux Surgery Study Group and then analyzed. Results: A total of 87 patients underwent laparoscopic fundoplication for the treatment of GERD. Preoperatively, typical symptoms were present in 81 patients (93\%) and atypical symptoms were present in 51 patients (59\%). Twenty-seven patients (31\%) had poor PPI responses. The average surgical time and postoperative hospital stay were $116.3 \pm 42.3$ minutes and $4.3 \pm 3.1$ days, respectively. At 3 months after surgery, typical symptoms were completely controlled in $86.3 \%$ of patients and partially controlled in $11.7 \%$, whereas atypical symptoms were completely controlled in $63.3 \%$ of patients and partially controlled in $23.3 \%$. Conclusions: This study showed that although atypical symptoms and PPI nonresponders are common, the complete control rates of typical and atypical symptoms were $86.3 \%$ and $63.3 \%$, respectively. Laparoscopic fundoplication is an efficacious method of controlling the symptoms of GERD and has an acceptable rate of postoperative morbidity and adverse symptoms. (Gut Liver 2016;10:726-730)

Key Words: Laparoscopic fundoplication; Gastroesophageal reflux disease; Proton pump inhibitors; Nationwide Korean data

\section{INTRODUCTION}

Gastroesophageal reflux disease (GERD) is one of the most common diseases of the gastrointestinal tract and is caused by chronic exposure of the esophagus to gastric contents. It reduces quality of life and causes various complications.

GERD affects $10 \%$ to $20 \%$ of the western population and 4.3\% to $15.7 \%$ of the Eastern Asia population. ${ }^{1}$ In addition, according to a nationwide survey, the incidence of GERD in Korea was 7.27\% in 2008 and is continuously increasing. ${ }^{2}$ After introduction of proton pump inhibitors (PPIs), medical therapy became the first-line therapy for chronic GERD and has high efficacy. However, not all patients with GERD respond to PPIs, and clinical failure to respond to PPIs occurs in 20\% to $45 \%$ of patients. ${ }^{3,4}$ Although GERD symptoms are improved while taking a PPI, repetitive relapses of symptoms can occur if a patient stops taking the PPI. Consequently, long-term control of GERD is necessary for these patients. Since laparoscopic Nissen fundoplication has been advocated for the treatment of GERD, ${ }^{5}$ laparoscopic fundoplication is regarded as an alternative treatment modality for GERD in Western countries. Several randomized studies have documented a better or similar effect of laparoscopic fundoplication compared to long-term PPI treatment, with $85 \%$ to $90 \%$ of patients being cured or showing significantly improved symptoms following laparoscopic fundoplication. ${ }^{6-10}$ On the other hand, the mainstay GERD treatment in Korea is long-term PPI use, and laparoscopic fundoplication is not yet a familiar treatment modality of Korean gastroenterologists and surgeons, possibly due to morbidity and concerns related to adverse symptoms after surgery. However, the advancements in minimally invasive surgical techniques for the treatment of GERD have decreased wound issues, morbidity, and hospital-

Correspondence to: Joong-Min Park

Department of Surgery, Chung-Ang University College of Medicine, 102 Heukseok-ro, Dongjak-gu, Seoul 06973, Korea

Tel: +82-2-6299-3124, Fax: +82-2-824-7869, E-mail: jmpark@cau.ac.kr

Received on August 20, 2015. Revised on November 16, 2015. Accepted on November 16, 2015. Published online April 28, 2016 pISSN 1976-2283 eISSN 2005-1212 http://dx.doi.org/10.5009/gnl15406

@) This is an Open Access article distributed under the terms of the Creative Commons Attribution Non-Commercial License (http://creativecommons.org/licenses/by-nc/4.0) which permits unrestricted non-commercial use, distribution, and reproduction in any medium, provided the original work is properly cited. 
ization duration and have allowed for a quicker return to daily life. Therefore, the Korean Antireflux Surgery Study (KARS) Group was organized in 2010 and has researched the safety and feasibility of laparoscopic antireflux surgery by conducting a nationwide survey.

The aim of the present study was to evaluate the nationwide KARS Group data and clinical outcomes and feasibility of laparoscopic antireflux surgery in Korea in the 4-year period following the organization of the KARS Group.

\section{MATERIALS AND METHODS}

A nationwide survey about the status of antireflux surgery in Korea was performed by the KARS Group in 2014, and included data from 2011 to 2014.

Eight surgeons from eight hospitals participated in this data survey. Data of 87 primary antireflux surgeries were collected. Patient characteristics, surgical procedures, surgery outcomes, postoperative complications and postoperative adverse symptoms were analyzed.

Our group made a questionnaire for GERD symptom evaluation. Typical and atypical GERD symptoms were explained to patients by doctors or educated nurses, and patients were asked to report any symptoms they had, including frequency and severity. Typical and atypical symptoms were recorded separately. Duration of GERD symptoms and information about PPI use were also collected.

GERD was diagnosed based on symptoms, endoscopy, barium esophagography, esophageal manometry, and 24-hour pH monitoring. A questionnaire designed to detect symptoms of GERD and to identify postoperative adverse symptoms of antireflux surgery was provided to patients at all hospitals at the time of discharge and 3 months after surgery.

GERD symptom resolution after surgery was scored as poor, fair, good, or excellent for typical and atypical symptoms. The score of "fair" was regarded as partial symptom control and the scores of "excellent and good" were regarded as complete symptom control, and the score "poor" was regarded as treatment failure.

The frequencies and severities of adverse symptoms after antireflux surgery, including dysphagia, difficult belching, gas bloating, and flatulence, were scored using a 5-point scale (no symptom-mild-moderate-severe-very severe).

\section{RESULTS}

\section{Characteristics of patients and procedures}

A total of 87 patients underwent primary laparoscopic fundoplication for treatment of GERD by eight Korean surgeons from January 2011 to July 2014. Preoperatively, typical symptoms (heartburn, regurgitation, and epigastric pain) were present in 81 patients (93\%), and atypical symptoms were present in 51 patients (59\%). Forty-five patients (51.7\%) had both typical and atypical symptoms. The mean duration of GERD symptoms was 69.6 months (range, 0 to 360 months). Twenty-seven patients (31\%) had a history of poor response to PPI therapy. The mean duration of PPI use was 31.1 months (range, 0 to 144 months) (Table 1).

All surgical procedures were performed laparoscopically, with no open conversions. Most surgeries were laparoscopic Nissen fundoplication, and one patient underwent Toupet fundoplication. Crural repair was performed by manual suturing with nonabsorbable suture material in 82 cases, and prosthetic repair was performed in five patients with giant hiatal hernias. The average surgical time was $116.3 \pm 42.3$ minutes (range, 47 to $290 \mathrm{~min}$ utes), and the average postoperative hospital stay was $4.3 \pm 3.1$ days.

Table 1. Patient Demographics and Baseline Characteristics

\begin{tabular}{|c|c|}
\hline Characteristic & Value \\
\hline Age, yr & $52.2 \pm 17.5$ \\
\hline Male/female & $41(47.1) / 46(52.9)$ \\
\hline Body mass index & $23.4 \pm 5.0$ \\
\hline Previous upper gastrointestinal surgery & $5(5.7)$ \\
\hline \multicolumn{2}{|l|}{ History of GERD symptoms, yr } \\
\hline$<1$ & $17(19.5)$ \\
\hline $1-5$ & $42(48.3)$ \\
\hline$>5$ & $28(32.2)$ \\
\hline \multicolumn{2}{|l|}{ Duration of PPI treatment, mo } \\
\hline$<6$ & $26(29.9)$ \\
\hline $6-12$ & $19(21.8)$ \\
\hline$>12$ & $42(48.3)$ \\
\hline \multicolumn{2}{|l|}{ GERD symptom } \\
\hline Only typical symptom & $36(41.4)$ \\
\hline Only atypical symptom & $6(6.9)$ \\
\hline Mixed symptom & $45(51.7)$ \\
\hline \multicolumn{2}{|l|}{ Los Angeles grade of esophagitis } \\
\hline Minimal or no esophagitis & $43(49.3)$ \\
\hline A & $29(33.3)$ \\
\hline $\mathrm{B}$ & $11(12.6)$ \\
\hline $\mathrm{C}$ & $3(3.4)$ \\
\hline $\mathrm{D}$ & $1(1.1)$ \\
\hline \multicolumn{2}{|l|}{ Hiatal hernia } \\
\hline No hiatal hernia & $45(51.7)$ \\
\hline Type 1 & $34(39.1)$ \\
\hline Type 2 & $4(4.6)$ \\
\hline Type 3 & $4(4.6)$ \\
\hline Barrett esophagus & $7(8.0)$ \\
\hline
\end{tabular}

Data are presented as mean \pm SD or number $(\%)$. 
Table 2. Postoperative Symptom Control Based on GERD Symptoms

\begin{tabular}{lccccc}
\hline \multirow{2}{*}{ Response } & \multicolumn{2}{c}{ Typical symptom } & & \multicolumn{2}{c}{ Atypical symptom } \\
\cline { 2 - 3 } \cline { 5 - 6 } Complete & Discharge $(\mathrm{n}=81)$ & P0 3m (n=51) & & Discharge $(\mathrm{n}=51)$ & P0 3m (n=30) \\
Partial & $55(86.4)$ & $44(86.3)$ & $6(11.7)$ & $36(70.6)$ & $19(63.3)$ \\
Not controlled & $23(9.9)$ & $1(2.0)$ & & $4(21.6)$ & $7(23.3)$ \\
\hline
\end{tabular}

Data are presented as number (\%).

GERD, gastroesophageal reflux disease; PO 3m, postoperative 3 months.

Table 3. Postoperative Symptom Control in Poor Responders

\begin{tabular}{|c|c|c|c|c|}
\hline \multirow{2}{*}{ Response } & \multicolumn{2}{|c|}{ Typical symptom } & \multicolumn{2}{|c|}{ Atypical symptom } \\
\hline & Discharge $(n=25)$ & P0 3m $(n=11)$ & Discharge $(n=14)$ & P0 3m (n=7) \\
\hline Complete & $15(60.0)$ & $6(54.5)$ & $7(50.0)$ & $3(42.9)$ \\
\hline Partial & $4(16)$ & $2(18.2)$ & $1(7.1)$ & $1(14.2)$ \\
\hline Not controlled & $6(24)$ & $3(27.3)$ & $6(43.9)$ & $3(42.9)$ \\
\hline
\end{tabular}

Data are presented as number (\%).

P0 3m, postoperative 3 months.

Table 4. Side Effects after Laparoscopic Antireflux Surgery

\begin{tabular}{|c|c|c|c|c|c|c|c|c|}
\hline \multirow{2}{*}{ Postoperative symptom } & \multicolumn{2}{|c|}{ Dysphagia } & \multicolumn{2}{|c|}{ Difficult belching } & \multicolumn{2}{|c|}{ Gas bloating } & \multicolumn{2}{|c|}{ Flatulence } \\
\hline & $\begin{array}{c}\text { Discharge } \\
(\mathrm{n}=87)\end{array}$ & $\begin{array}{l}\text { PO 3m } \\
(n=54)\end{array}$ & $\begin{array}{c}\text { Discharge } \\
(\mathrm{n}=87)\end{array}$ & $\begin{array}{l}\text { PO 3m } \\
(n=54)\end{array}$ & $\begin{array}{c}\text { Discharge } \\
(\mathrm{n}=87)\end{array}$ & $\begin{array}{l}\text { PO 3m } \\
(\mathrm{n}=54)\end{array}$ & $\begin{array}{c}\text { Discharge } \\
(\mathrm{n}=87)\end{array}$ & $\begin{array}{l}\text { PO 3m } \\
(n=54)\end{array}$ \\
\hline No or mild & $67(77)$ & 45 (83.3) & $69(79.3)$ & $48(88.9)$ & $74(85.1)$ & $42(77.8)$ & $78(89.7)$ & $43(79.6)$ \\
\hline Moderate to very severe & $20(23.0)$ & $9(16.7)$ & $18(20.7)$ & $6(11.1)$ & $13(14.9)$ & $12(22.2)$ & $9(10.3)$ & $11(20.4)$ \\
\hline p-value* & \multicolumn{2}{|c|}{0.016} & \multicolumn{2}{|c|}{0.022} & \multicolumn{2}{|c|}{1.000} & \multicolumn{2}{|c|}{0.581} \\
\hline
\end{tabular}

Data are presented as number (\%).

P0 3m, postoperative 3 months.

*McNemar test.

\section{Postoperative symptom control and side-effects}

After surgery, among the 81 patients who had typical GERD symptoms, the symptoms were completely controlled in 55 patients (86.4\%) and partially controlled in 23 patients (9.9\%). Among the 51 patients with atypical GERD symptoms, the symptoms were completely controlled in 36 patients (70.6\%) and partially controlled in 11 patients $(21.6 \%)$ at the time of discharge. These symptom control rates were maintained at 3 months after surgery (Table 2). In the subgroup analysis of 27 poor responders to PPI, 25 patients had typical GERD symptoms and 14 had both typical and atypical symptoms. Typical symptoms were completely and partially controlled in 19 patients (76\%) and eight patients (72.2\%), respectively, at both the time of discharge and 3 months after surgery. In contrast, atypical symptoms were completely and partially controlled in eight patients (57.1\%) and four patients (57.1\%), respectively, at both the time of discharge and 3 months after surgery (Table 3).

Twenty patients (23\%) developed postoperative dysphagia of moderate, severe, or very severe grade. This adverse symptom significantly decreased during the postoperative period, with
Table 5. Proton Pump Inhibitor Usage after Surgery

\begin{tabular}{lc}
\hline \multicolumn{1}{c}{ Reason } & No. of patients \\
\hline Persistent globus symptom & 3 \\
Reversal of wrap & 2 \\
Esophageal symptom & $1^{*}$ \\
Peptic ulcer & $1^{\dagger}$ \\
Helicobacter pylori eradication & $1^{\dagger}$
\end{tabular}

${ }^{*}$ Patient takes half dosage; ${ }^{\dagger}$ Stop proton pump inhibitor after resolve of problem.

only nine patients among 54 who were observed complaining of dysphagia at 3 months after surgery $(\mathrm{p}=0.016)$. Endoscopic dilation was required in one patient for postoperative dysphagia, and reversal of fundoplication by reoperation was required in two patients (Table 4).

Difficult belching also improved at 3 months after surgery compared to at the time of discharge $(\mathrm{p}=0.022)$, while gas bloating and flatulence had not changed at that time $(p=1.000$, and $\mathrm{p}=0.581$ ). Eight patients took PPIs after surgery, and the reasons for postoperative PPI use are listed in Table 5. 


\section{DISCUSSION}

Although the prevalence of GERD is relatively low in Korea, it has rapidly increased recently, as dietary habits have become more westernized. In Korea, GERD has recently been recognized as a significant health issue, and PPI usage is also increasing. ${ }^{2}$ GERD is defined as "a condition which develops when the reflux of stomach contents causes troublesome symptoms and/ or complications" by the Montreal consensus. ${ }^{11}$ GERD diagnosis can be confirmed by abnormal endoscopic findings, such as a mucosal break at the gastroesophageal junction, Barrett's esophagus on biopsy, peptic stricture in the absence of malignancy, and positive findings of 24-hour $\mathrm{pH}$ monitoring. The treatment for GERD is mainly medical therapy, including PPIs. Despite the high efficacy of PPIs for the treatment of GERD, the need for continuous PPI treatment and frequent relapses after terminating PPI use might discomfort patients, and it is known that PPIs may have no effect in 20\% to 45\% of GERD patients. ${ }^{3,4}$ These factors can negatively influence the quality of life of GERD patients and are important in the decision to perform antireflux surgery. Before the development of minimally invasive surgery, the invasiveness of open surgery made antireflux surgery a rarely indicated treatment option for GERD. However, due the introduction of minimally invasive surgery, antireflux surgery is now considered a more viable treatment option than in the past. Viljakka et al. ${ }^{12}$ reported that laparoscopic fundoplication was remarkably increased, approximately two-fold, after the introduction of minimally invasive surgery, as it generated good outcomes compared with the open procedure. According to the Society of American Gastrointestinal and Endoscopic Surgeons (SAGES) guidelines, antireflux surgery is indicated when the diagnosis of reflux is objectively confirmed in patients who (1) have failed medical management; (2) have opted for surgery despite successful medical management; (3) have complications of GERD; or (4) have extra-esophageal manifestations of GERD. ${ }^{13}$ Following this guideline, there are numerous reports of the efficacy of laparoscopic fundoplication for the treatment of GERD. ${ }^{7-10,14}$

However, in Korea, because of the uncertainty of the indications for antireflux surgery, the insufficient experience of surgeons, and the lack of data regarding antireflux surgery for the treatment of GERD, laparoscopic fundoplication has not been recognized and studied by Korean practitioners, even though the Korean expert consensus declared that antireflux surgery is especially useful for patients who require long-term PPI use or have refractory GERD, as described in the updated GERD treatment guidelines of $2012 .{ }^{15}$ To date, there have only been only two reports of 46 patients treated with antireflux surgery in Korea. ${ }^{16,17}$ All of those surgeries used the laparoscopic Nissen fundoplication technique, and the complete and partial symptom control rates were above 90\%. In contrast to the minimal research on antireflux surgery in Korea, many studies of the effectiveness of laparoscopic antireflux surgery have been conducted in western countries, and most randomized controlled trials have demonstrated similar or greater long-term improvement of GERD with antireflux surgery compared to treatment with drug-induced acid suppression with PPIs. ${ }^{7,10}$

In recent several years, along with the rapid increase in the incidence of GERD in Korea, the interest of Korean surgeons in antireflux surgery for the treatment of GERD, a benign upper gastrointestinal disease, also emerged. For this reason, the KARS Group was organized in 2010 by Korean upper gastrointestinal surgeons whose specialized field was gastric cancer surgery. The KARS Group had regular scientific conferences and hand-on workshops to allow the members to share each other's experiences and knowledge regarding GERD and antireflux surgery. This is the first report of a nationwide data about antireflux surgery collected by this group. In this study, the control rates of typical and atypical GERD symptoms immediately after and 3 months after surgery were not inferior to those of other reports, even though it was the very beginning period of antireflux surgery in Korea. ${ }^{6-10}$ These outcomes might result from the academic activity of KARS Group.

Typical symptoms of GERD (heartburn and regurgitation) and the symptomatic response to preoperative PPI therapy have been shown to be excellent predictors of good symptomatic response to antireflux surgery, and they are also prognostic predictors for medically treated patients. ${ }^{18}$

In the present study, a large portion of patients did not have heartburn or regurgitation, and one third of patients were PPI poor-responders. In the subgroup analysis of PPI poorresponders, the control rates for typical GERD and atypical GERD symptoms immediately and 3 months after surgery were lower than those of PPI good responders. Although these results were not compared with the results of medical therapy, laparoscopic antireflux surgery may be offered as the next line of management after failure of PPI therapy, especially for PPI poor-responders, if it is applied to carefully selected patients with refractory GERD. Regarding PPI usage after antireflux surgery, eight patients required readministration of a PPI. Among them, six reinitiated PPI use due to uncontrolled symptoms, and two temporarily took a PPI for a peptic ulcer and eradication of Helicobacter pylori. For six of the eight patients who required readministration of a PPI, three were PPI good-responders preoperatively and three were PPI poor-responders preoperatively with atypical symptoms. Because surgical treatment for GERD was unfamiliar to Korean gastroenterologists and surgeons, the preoperative evaluation for GERD patients in this study was somewhat insufficient. As a result, some of the patients in this study had many risk factors of poor surgical outcome; however, the symptom control rate and rate of postoperative side-effects related to fundoplication were comparable to those of previous reports from Korea and Western countries. Moreover, there was no mortality or surgical complications, such as bowel perfora- 
tion or bleeding, during the immediate postoperative period.

Recently, several new endoscopic devices and therapies have been devised to create a less invasive treatment in patients with GERD. Of these, the Stretta and EsophyX procedures have been currently performed for management of GERD because those are not so invasive and need not general anesthesia in comparison with antireflux surgery. According to the SAGES guideline, the Stretta procedure is regarded as an appropriate endoscopic treatment and it was reported that effectiveness of the Stretta procedure was not inferior to that of laparoscopic Toupet fundoplication. ${ }^{19,20}$ However, its effectiveness compared to antireflux surgery was not fully confirmed and further prospective studies may be required.

In conclusion, in the present nationwide dataset, although atypical symptoms and PPI poor-responders were common, the complete and partial symptom control rates were above 90\% during the short follow-up period. Laparoscopic fundoplication may be an efficacious method for controlling the symptoms of GERD in Korea. However, long-term evaluation of surgical results is needed to define the effectiveness of this surgery in Korea.

\section{CONFLICTS OF INTEREST}

No potential conflict of interest relevant to this article was reported.

\section{REFERENCES}

1. Jung HK. Epidemiology of gastroesophageal reflux disease in Asia: a systematic review. J Neurogastroenterol Motil 2011;17:14-27.

2. Kim KM, Cho YK, Bae SJ, et al. Prevalence of gastroesophageal reflux disease in Korea and associated health-care utilization: a national population-based study. J Gastroenterol Hepatol 2012;27: 741-745.

3. Becher A, El-Serag H. Systematic review: the association between symptomatic response to proton pump inhibitors and healthrelated quality of life in patients with gastro-oesophageal reflux disease. Aliment Pharmacol Ther 2011;34:618-627.

4. Fass R, Shapiro M, Dekel R, Sewell J. Systematic review: protonpump inhibitor failure in gastro-oesophageal reflux disease: where next? Aliment Pharmacol Ther 2005;22:79-94.

5. Dallemagne B, Weerts JM, Jehaes C, Markiewicz S, Lombard R. Laparoscopic Nissen fundoplication: preliminary report. Surg Laparosc Endosc 1991;1:138-143.

6. Lundell L, Miettinen P, Myrvold HE, et al. Seven-year follow-up of a randomized clinical trial comparing proton-pump inhibition with surgical therapy for reflux oesophagitis. Br J Surg 2007;94: 198-203.
7. Mahon D, Rhodes M, Decadt B, et al. Randomized clinical trial of laparoscopic Nissen fundoplication compared with proton-pump inhibitors for treatment of chronic gastro-oesophageal reflux. Br J Surg 2005;92:695-699.

8. Parrilla P, Martínez de Haro LF, Ortiz A, et al. Long-term results of a randomized prospective study comparing medical and surgical treatment of Barrett's esophagus. Ann Surg 2003;237:291-298.

9. Spechler SJ, Lee E, Ahnen D, et al. Long-term outcome of medical and surgical therapies for gastroesophageal reflux disease: followup of a randomized controlled trial. JAMA 2001;285:2331-2338.

10. Galmiche JP, Hatlebakk J, Attwood S, et al. Laparoscopic antireflux surgery vs esomeprazole treatment for chronic GERD: the LOTUS randomized clinical trial. JAMA 2011;305:1969-1977.

11. Vakil N, van Zanten SV, Kahrilas P, Dent J, Jones R; Global Consensus Group. The Montreal definition and classification of gastroesophageal reflux disease: a global evidence-based consensus. Am J Gastroenterol 2006;101:1900-1920.

12. Viljakka M, Luostarinen M, Isolauri J. Incidence of antireflux surgery in Finland 1988-1993: influence of proton-pump inhibitors and laparoscopic technique. Scand J Gastroenterol 1997;32:415418.

13. Stefanidis D, Hope WW, Kohn GP, et al. Guidelines for surgical treatment of gastroesophageal reflux disease. Surg Endosc 2010; 24:2647-2669.

14. Fernando HC, Schauer PR, Rosenblatt M, et al. Quality of life after antireflux surgery compared with nonoperative management for severe gastroesophageal reflux disease. J Am Coll Surg 2002;194:23-27.

15. Jung HK, Hong SJ, Jo YJ, et al. Updated guidelines 2012 for gastroesophageal reflux disease. Korean J Gastroenterol 2012;60:195218.

16. Lee SB, Jeon KM, Kim BS, Kim KC, Jung HY, Choi YB. Early experiences of minimally invasive surgery to treat gastroesophageal reflux disease. J Korean Surg Soc 2013;84:330-337.

17. Lee SK, Kim EK. Laparoscopic Nissen fundoplication in Korean patients with gastroesophageal reflux disease. Yonsei Med J 2009;50:89-94.

18. Campos GM, Peters JH, DeMeester TR, et al. Multivariate analysis of factors predicting outcome after laparoscopic Nissen fundoplication. J Gastrointest Surg 1999;3:292-300.

19. Auyang ED, Carter P, Rauth T, Fanelli RD; SAGES Guidelines Committee. SAGES clinical spotlight review: endoluminal treatments for gastroesophageal reflux disease (GERD). Surg Endosc 2013;27:2658-2672.

20. Liang WT, Yan C, Wang ZG, et al. Early and midterm outcome after laparoscopic fundoplication and a minimally invasive endoscopic procedure in patients with gastroesophageal reflux disease: a prospective observational study. J Laparoendosc Adv Surg Tech A 2015;25:657-661. 